\title{
A dynamic model of decision-making under cognitive dissonance and modularity of mind
}

Citation for published version (APA):

Karagozoglu, E. (2010). A dynamic model of decision-making under cognitive dissonance and modularity of mind. METEOR, Maastricht University School of Business and Economics. METEOR Research Memorandum No. 014 https://doi.org/10.26481/umamet.2010014

Document status and date:

Published: 01/01/2010

DOI:

10.26481/umamet.2010014

Document Version:

Publisher's PDF, also known as Version of record

\section{Please check the document version of this publication:}

- A submitted manuscript is the version of the article upon submission and before peer-review. There can be important differences between the submitted version and the official published version of record.

People interested in the research are advised to contact the author for the final version of the publication, or visit the DOI to the publisher's website.

- The final author version and the galley proof are versions of the publication after peer review.

- The final published version features the final layout of the paper including the volume, issue and page numbers.

Link to publication

\footnotetext{
General rights rights.

- You may freely distribute the URL identifying the publication in the public portal. please follow below link for the End User Agreement:

www.umlib.nl/taverne-license

Take down policy

If you believe that this document breaches copyright please contact us at:

repository@maastrichtuniversity.nl

providing details and we will investigate your claim.
}

Copyright and moral rights for the publications made accessible in the public portal are retained by the authors and/or other copyright owners and it is a condition of accessing publications that users recognise and abide by the legal requirements associated with these

- Users may download and print one copy of any publication from the public portal for the purpose of private study or research.

- You may not further distribute the material or use it for any profit-making activity or commercial gain

If the publication is distributed under the terms of Article $25 \mathrm{fa}$ of the Dutch Copyright Act, indicated by the "Taverne" license above, 


\section{Maastricht University}

Emin Karagözoğlu

A Dynamic Model of Decisionmaking Under Cognitive

Dissonance and Modularity of Mind

$\mathrm{RM} / 10 / 014$

\section{METEOR}

Maastricht University School of Business and Economics

Maastricht Research School of Economics

of Technology and Organization

P.O. Box 616

NL - 6200 MD Maastricht

The Netherlands 


\title{
A Dynamic Model of Decision-making Under Cognitive Dissonance and Modularity of Mind*
}

\author{
Emin Karagözoğlu ${ }^{\dagger}$ \\ Maastricht University, Department of Economics
}

July, 2009

\begin{abstract}
This paper attempts to explain how and why seemingly contradictory beliefs co-exist in an optimizing individual's mind in the long run. We set up a dynamic model of decision-making in which the individual's mind is composed of a coordinating principal and two conflicting agents. We take into account the cognitive dissonance experienced due to the conflict between the agents. Each agent (or self) is specialized in perceiving a particular type of signal, which describes the world. Cognitive dissonance levels in our model are not constant. Instead, the individual's split-selves are open to habituation, which can lead to a reduction in cognitive dissonance. We prove the existence of an optimal strategy with a threshold structure. Our results show that the co-existence of conflicting beliefs might be an equilibrium phenomenon even in an optimizing mind. Suggestions that may avoid the tension that occurs due to cognitive dissonance are made. Keywords: Cognitive Dissonance, Modularity of Mind, Habituation, Stochastic Dynamic Programming.
\end{abstract}

JEL Classification Numbers: A12, C61, D90, D81, D83

${ }^{*}$ I owe special thanks to Kalyan Chatterjee and Arno Riedl for their invaluable help and supervision during this project. I would also like to thank Zafer Akın, Simon Gächter, İsa Emin Hafalır, Jeffrey A. Kurland, Ayşe Tever Karagözoğlu, Abdullah Yavaş, Hale Utar, and seminar participants at Maastricht University, Boğaziçi University, and Conference of the French Economics Association on Behavioral Economics and Experiments for their helpful comments. Usual disclaimers apply.

${ }^{\dagger}$ Contact Info: Maastricht University, Department of Economics, P.O. Box 616, 6200 MD, Maastricht, The Netherlands. Phone : +31 (0) 433883925 Fax: +31 (0) 4338848 78. Email: E.Karagozoglu@maastrichtuniversity.nl. 
Cognitive Dissonance: - psychological conflict resulting from incongruous beliefs and attitudes held simultaneously.

Habituation: - decrease in responsiveness upon repeated exposure to a stimulus.

(Merriam-Webster Dictionary)

\section{Introduction}

\subsection{Motivation}

"I was lucky", "It was not very difficult after all", "Nothing to mention", "Anyone would do the same thing". Why do most of us show signs of humbleness when others express their admiration or gratitude towards us in relation to our success in a task or an effort in helping others. Is it only due to the values the society attach to being humble? Or is there also something about our inner struggle in the background?

And why do most some people repetitively involve in actions they complain about and regret for later? Is it only due to the hot-cold phenomenon? Or is there also something about the acceptable amount of intra-personel conflict? Can it be that this action-regret cycle is an equilibrium product of an optimizing mind?

In this paper we seek to analyze the decision-making behavior of an individual whose choices are partially constrained by cognitive dissonance. Our research questions are: (i) What is the behavior of an optimizing individual in a dynamic setting in which there are states of the world that cause cognitive dissonance and correspondingly a fall in individual's decision-making performance? (ii) What is the evolution of cognitive dissonance on an optimal decision path when habituation is present?, and (iii) What are the factors that affect the equilibrium level of cognitive dissonance in an optimizing individual's mind?

The motivation for our study stems from the fact that stress and tension due to conflicting beliefs or actions are experienced more frequently and repetitively than one would expect. This raises the question: Can cognitive dissonance and intra-personal conflict be equilibrium phenomena? If they are, which factors have an impact on the equilibrium level of conflict an individual bears in mind? What is the influence and role of habituation on the evolution of the level of intra-personal conflict? To answer these questions, we model mind as a decision-making unit with a modular structure, which is aware of the dynamic and flexible aspect of the conflict between its different-selves and acts accordingly. In particular, it foregoes higher payoffs in some states of the world to be able to reduce the cognitive dissonance it experiences due to the conflict that occurs in some other states of the world. The concept of habituation, which implies that cognitive dissonance might change as a result of being repetitively exposed to the dissonance creating state/signal is a corner stone of our model. In that sense, our paper is different from most of the others in the economics literature, since it models cognitive dissonance and its evolution rather than applying this notion to an economic decision problem. The dynamic character of the model allows us to analyze the impact of relevant parameters on the evolution of intra-personal conflict.

Our model incorporates the fact that mind $^{1}$ is not a seamless unit, but rather a modular one (see Minsky, 1986). It has different parts in a hierarchical structure, which are specialized in certain

\footnotetext{
${ }^{1}$ We try to avoid using terms mind and brain interchangeably. However, there are some parts of the paper where they are used interchangeably because the literatures we mention to support our assumptions has done so.
} 
tasks and responsive to only particular signals. In our model, there is an organizing unit (the principal) and two different units in a lower hierarchy (agents). ${ }^{2}$ Each of those agents (which can be thought as different selves of the individual) has a comparative advantage in receiving one signal. When the signal describing the world arrives, the principal assigns it to one (or both in some cases) of the agents who performs a task. The task that agents perform can be interpreted as a simple binary decision. If the signal is perceived, the agent is successful in performing the task, which brings a positive payoff (or utility) to the individual. The principal's decision in each period can be reduced to choosing one of the following actions: attempting cross-training or acting in accordance with the agents' specializations. Cross-training aims at reducing cognitive dissonance levels by exposing the agents to characteristics of the world they do not "like" and are not specialized in perceiving. Acting in accordance with agents' specializations is just assigning the signal to the agent who is specialized in it. Even though there is a current cost associated with cross-training, it might lead to lower dissonance levels in the future due to habituation. The benefit from cognitive dissonance is obtained in the composite state of the world when the principal needs both agents to act together. This is due to the fact that cognitive dissonance is felt when those two agents have to act together. Acting in accordance with specializations leads to a higher expected current payoff, but does not reduce dissonance levels. Therefore, there is a trade-off associated with current and future payoffs for the principal.

To be able to understand our scenario more clearly, the following example might be useful. Think of an economist with expert and layman selves. The expert-self fonds of scientific rigor, formality and, concrete statements and.is against any compromise on these. On the other hand, the layman-self fonds of more general statements and less formality and details. ${ }^{3}$ States of the world are characterized by the audience to which the economist delivers a speech: in the first state of the world, he needs to deliver a speech to a specialist audience $A$, whereas in the second state of the world he needs to deliver a speech to a public audience $B$ with different characteristics. In the composite state, the audience is much more crowded and a mixture of types $A$ and $B$. Over an infinite life horizon, these states of the world are recurrent with given frequencies. The economist's aim is to maximize a life-time utility that arises from convincing the audience. Therefore, the principal's decision at each period is to choose which agent (self) to employ. For instance, should he give up formalities and details and make more general statements while he is delivering it to a specialist audience, or should he talk with complete scientific rigor, emphasizing the assumptions, details, etc.? This corresponds to choosing between cross-training or acting in accordance with specializations. The first one brings a lower expected current payoff but is more promising in reducing cognitive dissonances; and the latter one has a higher expected current payoff but is not expected to reduce cognitive dissonance.

\section{$1.2 \quad$ Related Literature}

Festinger (1957) asserts that people experience cognitive dissonance when they hold inconsistent beliefs, or act contrary to their beliefs. Since the tension brought by this inconsistency between

\footnotetext{
${ }^{2}$ The reader is referred to Hughlings-Jackson (1959) and Minsky (1986) for seminal contributions on this kind of hierarchical structure in mental and neurological organization.

${ }^{3}$ For instance, if the economist will deliver a speech about the Nash equilibrium, the expert-self might first like to distinguish between pure strategies and mixed strategies and explain each condition necessary for their existence in detail (e.g., the epistemics of common belief in rationality), whereas the layman-self might skip all of these "details" and say "Nash equilibrium almost always exist".
} 
beliefs and/or actions is not a pleasant state, individual wants to eliminate it either by changing his/her beliefs or actions. Aronson (1988) and Beauvois and Joule (1996) among the authors in the modern theory of cognitive dissonance claim that dissonance is mainly related to the issues of self-esteem and the desire to rationalize one's actions. In other words, the dissonance and dissonance reducing behavior generally exist when an individual's actions or beliefs are in conflict with his/her desire to be known as a good or an intelligent individual. This argument is complementing Festinger's (1957) original theory of cognitive dissonance in a way that it emphasizes the main source of dissonance.

The first economic paper that deals with possible economic consequences of cognitive dissonance is Akerlof and Dickens (1982). Their model predicts not only how a given information is interpreted, but also whether that information is to be received or not according to their preferences. With the cognitive dissonance approach, they can explain the effectivity of non-informational advertising, the popularity of social security legislation and safety legislation and the failure of people in purchasing actuarially beneficial flood and earthquake insurance. Moreover, these explanations are not based on the assumption that people are misinformed but rather on the assumption that if they believe in something other than the truth, they prefer to do so by their own choice. Dickens (1986) proves, in a model of criminal behavior which considers the effects of cognitive dissonance, that increasing the severity of punishment could increase the crime rate. The intuition for this result is that with cognitive dissonance, people may have to rationalize not committing crimes under normal circumstances, if punishment is not severe. The rationalization may lead them to underestimate the expected utility of committing crimes when opportunities present themselves. If punishment is severe, then rationalization may not be necessary and people may be more likely to commit crimes when opportunities arise.

Gilad et al. (1987) analyze an individual's utility maximization problem with the additional feature of an information filter that represents selective exposure to information or evidence as a way of avoiding cognitive dissonance. They explain some of the well-known 'irrational behavior' such as the stock-market investment behavior, the Phillips Curve and effects of sunk costs on investment decisions. Rabin (1994) models social change, taking cognitive dissonance into account and reaches seemingly counter-intuitive conclusions. He indicates that an increase in people's dislike for acting immorally can lead to an increase in the level of immoral activities when one's belief has an impact on the beliefs of others. This is due to cognitive dissonance people experience and stems from the fact that in such a situation people will feel an obligation to persuade themselves that immoral activities are in fact moral. Brady et al. (1995) argue, in particular as a response to Akerlof and Dickens' (1982) policy suggestion about labor market safety regulations, that the cognitive dissonance is also a relevant phenomenon for public sector authorities. Accordingly, they suggest that delegating the decisions about work safety equipment to some government authority may not solve the problem as Akerlof and Dickens (1982) proposed. Konow (2000) analyzes the impact of cognitive dissonance on fairness concerns in individuals' allocation decisions in an experimental setup. His results indicate that cognitive dissonance can explain fairness considerations in dictator games. Oxoby (2003) incorporates cognitive dissonance into a model that explains status-seeking behavior. Since individual's utility depends on "How she sees herself" and this self-image is affected by her status in the society, cognitive dissonance theory has a potential to contribute to the analysis of status-seeking behavior. Johansson-Stenman and Svedsäter (2008) find, in an experimental setting, that people tend to act in a cognitively consistent manner even though it sometimes may not be in line with their material well-being. 
To the best of our knowledge, Epstein and Kopylov (2006) is the only axiomatic study of cognitive dissonance in economics. They model self-justification of past decisions. Axioms are defined on preferences over ex-ante actions (modeled formally by menus). The representation of these preferences admits the interpretation that the agent adjusts beliefs after taking an action so as to be more optimistic about its possible consequences. Since the action has already been taken, no adjustment can be made on it. Therefore, the individual adjusts his/her beliefs taking actions as given.

\subsection{Contribution}

Solving for the principal's stochastic dynamic programming problem, we find that (i) a forwardlooking principal uses a threshold rule in deciding whether to assign the task to the agent which is specialized in the given state or attempting cross-training. (ii) A direct implication of this finding is that for some parameter values, it is not optimal for the agent to reduce dissonance to its minimum level. Therefore, the main message of this paper is that under certain circumstances, which will be described in terms of the parameters of the model, the conflict might remain in an optimizing mind, which implies that cognitive dissonance can be a long-term phenomenon. (iii) The individual's defining characteristics and behavior is affected by the comparative flexibility of his different selves. (iv) The pace of habituation, the time preference, and the frequency of the composite state with conflict are some important factors affecting the optimal decision. In particular, an increase in the pace of habituation, the discount parameter, and the frequency of conflict have the same kind of impacts. They all increase the expected benefit from attempting cross-training. Therefore, an increase in any of those parameters reduces the equilibrium level of dissonance.

Most of the contributions of our model lie in its rich behavioral structure. First of all, to the best of our knowledge, the model in this paper is the first dynamic model of individual decision-making under cognitive dissonance. Accordingly, it allows us to analyze more realistic long-run decision dynamics. Secondly, it is an economic model that incorporates many behavioral phenomena such as habituation, modularity of mind, and cognitive dissonance to an individual decision-making problem. Moreover, the model presented here can explain the persistence of conflict, and hence the existence of conflicting beliefs in the long run, whereas the other papers in the literature cannot offer an explanation to this kind of phenomenon. Finally, due to its rich structure, our model can provide useful policy implications also for the resolution of inter-personal conflict.

\subsection{Roadmap}

The paper is organized as follows. In section 2, we introduce our model, the cross-training attempts and the value function. Section 3 presents some preparatory results and the main result of the paper. In section 4, we conduct comparative static analyses on relevant parameters and explain the results from an intuitive perspective. Section 5 discusses some of the assumptions of our model and offer some extension ideas. Section 6 ends the paper with concluding remarks.

\section{The Model}

Modularity of Mind: Our model of decision-making in human mind stems from ideas and findings in two literatures. Findings in neuroscience and the cognitive science literature suggests that the 
mind is not a seamless unit. Rather, it is composed of semi-autonomous parts each of which is specialized in receiving certain signals and performing certain tasks. This implies a modularity of mind in cognitive activity. One of the major points Minsky's (1986) Society of Mind makes is this collective but specialized structure of human mind. Fodor (1983), Pinker (1997), and Shettleworth (1998) are some others, who mention the modularity of the mind. A well-known example in neuroscience is due to McClure et al. (2004), finding that the limbic system responds more to immediate gratification whereas the cortical system responds to longer-term benefits. Brocas and Carillo's (2008) model rests upon this intra-personal conflict of preferences within each period between two separate entities or systems in the brain. To summarize, the modularity of mind (or brain) is a well-known and a widely accepted phenomenon. In economics, multiple-selves approach, which is in line with this phenomenon has been used extensively in recent years. People have different traits or characteristics which are specialized in different signals, tasks and responsive to different types of urges. In theoretical biology, Byrne and Kurland (2001) name those units that respond to different urges as "daemons".

Hierarchy: Another important finding that is relevant for our model is that there is a hierarchy in mind. Some systems or parts have superior positions in this decision-making hierarchy. Accordingly, we assume that there is a governing unit, which we label as the principal and two semi-autonomous agents embedded in the mind of the individual in our model. ${ }^{4}$ The principal has a higher place in the hierarchy compared to the agents. We denote the principal as $P$ and those agents are denoted as $A_{i}, i=1,2$.

States of the World and Specialization: In our model, there are signals, which partition the information space, i.e. describe the state of the world. States of the world are characteristics of the world, which are described by signals. Therefore, we do not use the term "state of the world" to refer to different physical states of the world. Instead, they are different aspects or characteristics of a unique physical state of the world. We assume that there are two pure characteristics of the world, denoted by $S_{j} \in\left\{S_{1}, S_{2}\right\}$ that can be described by signals. Signals are defined on the power set of these. We denote signals by $s_{j}$, where originally $s_{j} \in\left\{s_{1}, s_{2}, s_{3}, s_{4}\right\}$. The possible signals are:

$$
\begin{aligned}
& s=s_{1} \rightarrow\left\{s_{1}\right\} x S_{2}, \\
& s=s_{2} \rightarrow S_{1} x\left\{s_{2}\right\} \\
& s=s_{3}=\left\{s_{1}, s_{2}\right\} \rightarrow\left\{s_{1}\right\} x\left\{s_{2}\right\}, \text { and } \\
& s=s_{4}=\emptyset \rightarrow S_{1} x S_{2}
\end{aligned}
$$

where the first case corresponds to receiving a signal that gives information only about $S_{1}$, the second one corresponds to receiving a signal that gives information only about $S_{2}$, the third one implies that the signal received gives information about both $S_{1}$ and $S_{2}$, and the last one implies that the signal received gives information neither about $S_{1}$ nor $S_{2}{ }^{5}$

\footnotetext{
${ }^{4}$ This is similar to the Planner - Doer interpretation in Thaler \& Shefrin (1981) and Bénabou \& Pycia (2002). The hierarchical and modular structure described in Minsky (1986), Oatley (1986) and Blakeslee (2005) are also in line with our model.

${ }^{5}$ To clarify the meaning of characteristics of the world and signals, the following example might be helpful. Assume that a person is asked to guess someone's age using the signal (or information) she is given. Potentially, she has two signal sources: person's voice (audio signal) and look (visual signal). If she only sees (hears) the person, then she only receives a visual (audio) signal. If she both sees and hears the person, then she receives both signals. And if she neither sees nor hears the person, this corresponds to receiving no signal.
} 
Each agent $A_{i}$ has a comparative advantage in perceiving one pure signal $s_{j}$, where $j=1,2$. The specialization (or the comparative advantage) is associated with agents' perception quality. Agent $A_{i}$ perceives the signal that he is specialized in with probability $\bar{P}$ and the signal that he is not specialized in with probability $\underline{P}$, where $\bar{P}+\underline{P}=1$ and $\bar{P}>\underline{P}$.

In each period $t$, a signal arrives the principal, which is then assigned to one or both of the agents. By assigning the signal, the principal employs one (or both) of the agents in the decisionmaking. Here, we do not model the task explicitly, but it can be interpreted as making a decision given the signal in the current period. If the signal is successfully perceived, the task will be performed successfully, which brings a payoff of 1 (or 2 in the case of a composite signal) to the individual; if the agent who is delegated cannot perceive the signal successfully, then he cannot perform the task successfully, which leads to 0 payoff for the individual. Payoffs can be interpreted as any kind of benefits from the successful completion of the task. They can be monetary payoffs or utilities in general.

Cognitive Dissonance: The cognitive dissonance comes into the picture in the case of a composite signal, $s_{3}$. The composite signal describes two different aspects of the world, which in turn requires both agents to work together. Without both of them performing, the task in $s_{3}$ cannot be successfully completed. However, since those two agents are in conflict with each other, their simultaneous involvement creates a cognitive dissonance, which influences individual's payoff negatively. ${ }^{6}$ Cognitive dissonance that is due to agent $A_{i}$ is denoted as $\theta_{i}$.

While we are describing this modular structure found in scientific research, we would also like to mention the possibility of conflict among different parts of the brain. Conflicting interests of the different parts of the mind/brain is also a well-documented phenomenon in neuroscience and psychology. Among all, Minsky (1986), Mischel et al. (1989), McClure et al. (2004), Tversky and Shafir (1992), Camerer et al. (2005) are some studies that report the existence of a conflict between different mental and neural systems. In a recent theoretical paper, Livnat and Pippenger (2006) argues that optimal brain system which is designed for a sole purpose can have agents which are in conflict with each other. The conflict reported in these studies is one of the corner stones of our model. It is the existence of this conflict, which leads to cognitive dissonance. Although most of the papers mentioned above refer to the modular structure of the brain, the existence of split-selves, conflicting beliefs or urges can always be given as examples for the modularity of mind.

Costs of Intra-personal Conflict: A phenomenon, which is directly related to conflict and cognitive dissonance is the tension and the corresponding fall in performance. A useful example comes from a well-known psychological test, Stroop test named after John Ridley Stroop: Blakeslee (2005) analyzes the nature of hypnosis and suggestion on subjects' decision-making performance in a psychological experiment. Subjects are shown cards on which there are colored writings and asked to press a button to tell the color of the writing. The trick in the experiment is that writings conflict with the colors e.g., the word blue is written in red or "yellow" is written in green. In this experiment, it has been observed that subjects sometimes spend some time to tell the color and

\footnotetext{
${ }^{6}$ The reader should notice that the cognitive dissonance that can be experienced due to the conflict of decisions made in different periods is not the focus of this paper. Hence, we do not explicitly model the cognitive dissonance that might arise when the principal assigns $s_{1}$ to (let's say) $A_{1}$ at period $t$ and $s_{2}$ to $A_{2}$ at period $t+1$. Gur \& Sackheim's (1979) definition of self-deception as a motivated act is an appropriate explanation for this phenomenon. The fact that some brain areas (including consciousness) may be unaware of information to which other brain areas respond is a well-established phenomenon in neuroscience (see Berns et al., 1997 and Whalen et al., 1998).
} 
sometimes even tell the wrong color. The color signal and the word signal create a conflict in the brain. This is called the Stroop effect. She reports that hypnosis and suggestion stop this conflict by suppressing the parts of the brain that is responsible for reading and detecting conflict. Aside from the hypnosis part, the conflict and the Stroop effect in her study are very much related to the structure of our model. The very existence of conflict, let it be among different urges, beliefs, signals, or agents, almost always reduces the performance.

Before we describe the cross-training phase and the value function, we present the time-line of events, below.

\begin{tabular}{cl}
\hline$t$ & \multicolumn{1}{c}{$t+1$} \\
$*$ Signal arrives & $*$ Changes in dissonances \\
$*$ Assignment is made & are observed \\
$*$ Outcome is realized & $*$ New signal arrives
\end{tabular}

Figure 1: Time-Line of Events

\subsection{Cross-Training Attempts}

The motivation for incorporating the cross-training phase into the model is a psychological phenomenon called habituation. The term habituation in the psychology literature refers to the decline of a conditioned response following repeated exposure to the conditioned stimulus. Some examples would be:

- When a subject in an experiment is given an electric shock repetitively with the same magnitude, the experimenter needs to increase the magnitude of the shock to get a response that is equivalent to the one at the beginning.

- Old people who react to social changes, fashion and the habits of a new generation start to get used to them if they are frequently exposed to these phenomena.

- An individual who thinks that lying is not a good behavioral trait, might feel less cognitive dissonance if he occasionally has to lie in his new job.

- A burglar might hesitate and hence act slow and sloppy in his first burglary; but after years, he might get used to the idea of stealing and acts very fast and professionally.

Habituation is a type of defense mechanism for the individual to avoid the unpleasant feeling he/she experiences. The reason is the tension that occurs in the case of dissonance. If a particular action (or belief) is in contradiction with some other and is comparatively more crucial for the individual, he/she needs to adjust the latter one accordingly so that he/she feels less dissonance. Habituation may take place consciously or unconsciously.

Habituation is an important part of our model since it creates a trade-off for the individual, which makes his/her decision problem a dynamic one. The effect of habituation is observed on dissonance parameters, i.e., $\theta_{i}, i=1,2 . \theta_{i}$ 's are discrete, one-to-one, and bounded functions of successful cross-training attempts in the model. If an agent is loaded with the signal that he is not specialized in and if he perceives the signal successfully, it decreases his cognitive dissonance that he experiences in the composite state. Hence, for all $i, \frac{\Delta \theta_{i}}{\Delta n_{i}}<0$ at each point (where $n_{i}$ is 
the number of successful cross-training attempts) except the lower bound, 0. Moreover, we assume that the lower bound 0 can be reached with finitely many successful cross-training attempts.

In the composite state, the principal needs both agents to be able to perform the task successfully and when both agents act together in the same time period on the same task, they experience cognitive dissonance due to their awareness of the "other". It is very similar to the concept of negative externality in some economic problems. In a sense, those two agents impose a negative externality on each other. We assume that cognitive dissonance is experienced only in the case of successful completion of the task, which requires perception of both parts of the composite signal. In a sense, successful perception of the signal by one agent guarantees the other agent's awareness of the agent's active involvement.

The possibility of reducing cognitive dissonance in composite states raises a question for the principal. The probability of receiving signal $s_{j}$, where $j=1,2,3$ is independent and identical across time and equal to $F_{j}=\frac{1}{3}$ for all $j=1,2,3 .{ }^{7}$ Therefore, the principal should decide whether to act in accordance with specializations or attempt cross-training, when he receives the signal $s_{j}$, $j=1,2$.

Having described the important notions in the model, below we define the individual's value function.

\subsection{The Value Function}

The expected current payoff levels under different signals and assignments are presented below for the reader to be able to follow easily. For instance, the first cell can be read as the expected payoff if $s_{1}$ is assigned to $A_{i}$, who is specialized in $s_{1}{ }^{8}$

\begin{tabular}{|c||c|c|c|}
\hline & $A_{i}$ specialized in $s_{1}$ & $A_{i}$ specialized in $s_{2}$ & Both Agents \\
\hline \hline$s_{1}$ & $\bar{P} .1+(1-\bar{P}) .0$ & $\underline{P} .1+(1-\underline{P}) .0$ & $N A$ \\
\hline$s_{2}$ & $\underline{P} .1+(1-\underline{P}) .0$ & $\bar{P} .1+(1-\bar{P}) .0$ & $N A$ \\
\hline$s_{3}$ & 0 & 0 & $((\bar{P} \bar{P})+(\underline{P P})) .2-(\overline{P P})\left(\theta_{1}+\theta_{2}\right)$ \\
\hline
\end{tabular}

Table 1: Immediate Payoffs

Now, we can write the principal's value function. The principal's problem at each period is to determine which agent(s) he should assign the signal (or the task) in the given state:

$$
\begin{aligned}
& V\left(j, \theta_{1}, \theta_{2}\right)=\max \left\{\begin{array}{c}
\bar{P}+\beta E V_{\max }\left(j^{\prime}, \theta_{1}^{\prime}, \theta_{2}^{\prime}\right), \\
\underline{P}+\beta E V_{\min }\left(j^{\prime}, \theta_{1}^{\prime}, \theta_{2}^{\prime}\right)
\end{array}\right\}, \text { if } j=1,2 \\
& V\left(j, \theta_{1}, \theta_{2}\right)=\max \left\{\begin{array}{c}
(\bar{P} \bar{P})\left(2-\theta_{1}-\theta_{2}\right)+\beta E V_{N N}\left(j^{\prime}, \theta_{1}^{\prime}, \theta_{2}^{\prime}\right), \\
0+\beta E V_{Y N}\left(j^{\prime}, \theta_{1}^{\prime}, \theta_{2}^{\prime}\right), \\
0+\beta E V_{Y N}\left(j^{\prime}, \theta_{1}^{\prime}, \theta_{2}^{\prime}\right), \\
(\underline{P} \underline{P})\left(2-\theta_{1}-\theta_{2}\right)+\beta E V_{Y Y}\left(j^{\prime}, \theta_{1}^{\prime}, \theta_{2}^{\prime}\right)
\end{array}\right\}, \text { if } j=3
\end{aligned}
$$

\footnotetext{
${ }^{7}$ Since the signal that does not describe any characteristic of the world, i.e., $s_{4}=\emptyset$ is not operational in any sense, we assigned $F_{4}=0$.

${ }^{8}$ We assume that for a singleton signal such as $s_{j}, j=1,2$, the trade-off is between deciding in accordance with specializations and attempting cross-training. Therefore, assigning the task in the presence of $s_{1}$ or $s_{2}$ to both agents is not an option. This is more of a simplifying assumption to keep the model tractable.
} 


$$
\text { given } \theta_{i}\left(n_{i}\right) \text { for } i=1,2 \text {, }
$$

where $V_{\max }$ refers to next period's value function when the task in the current state $j$ is assigned to the agent specialized in state $j$ and $V_{\min }$ refers to next period's value function when the task in the current state $j$ is assigned to the agents not specialized in state $j$. When $j=3$, there are four different options for the principal:

- Assigning in accordance with specializations for both signals,

- cross-training $A_{1}$ and not cross-training $A_{2}$

- not cross-training $A_{1}$ and cross-training $A_{2}$, and

- cross-training both $A_{1}$ and $A_{2}$.

Subscripts $N N, Y N, N Y, Y Y$ correspond to those options, respectively. In $Y N$ and $N Y$, since one of the signals is not assigned, it will not be perceived for sure. Therefore, the current payoff is 0 . Expectations in the next period value functions are taken on $j$ and $\theta_{i}$ 's. The reason for taking expectations on $\theta_{i}$ 's is the stochastic perception of agents. Other than that, $\theta_{i}$ 's follow a known deterministic process (function of number of successful cross-training attempts) and they take values in $[0,1]$ interval. Also, note that $n_{i}$ 's need not to be state variables since given $\theta_{i}\left(n_{i}\right)$ functions, once $\theta_{i}$ is observed, principal knows the value of $\theta_{i}\left(n_{i}+1\right)$. The fact that $\theta_{i}\left(n_{i}\right)$ are one-to-one functions is useful here.

\section{The Equilibrium}

The two lemmas below provide some preliminary results to be used in the main theorem. The first lemma suggests that there exists a certain point in time, after which there is no expected future benefits from cross-training, which implies that the principal decides solely based on agents' specializations.

Lemma 1 The probability that there exists a finite period $T$ after which "acting in accordance with specializations" is the unique optimal action for all $t$ is 1.

Proof. See Appendix.

The lemma below suggests that there is no reason to wait for cross-training if there are expected future benefits from doing so.

Lemma 2 It is not optimal to attempt to cross-train $A_{i}$ in the future, if it is not optimal now.

Proof. See Appendix.

The following theorem presents our main result. It encapsulates that the optimal decision rule for the principal follows a threshold structure.

Theorem 1 (Main Theorem) Given the stochastic dynamic programming problem in (1) and (2), the optimal decision rule has the following threshold structure with crucial values of $\theta_{i}, \bar{\theta}_{i}$ for $i=1,2$ : 
- Attempt cross-training in state $j=1,2$ if $\theta_{i} \geq \bar{\theta}_{i}$ where agent $i$ is the one, not specialized in state $j$ and

- Act in accordance with specializations if $\theta_{i}<\bar{\theta}_{i}$.

The difficulty of solving the stochastic dynamic programming problem given above stems from the fact that the evolution of the stochastic processes in the future depends on the current decision. Therefore, it is not a stationary stochastic dynamic programming problem that can be solved easily by equating the expected payoffs that are due to different decisions to each other. However, Lemma 1 and Lemma 2 stated above are useful in proving this proposition. The facts we exploit are (i) After a finite period of time, the problem becomes stationary (see Lemma 1) and (ii) postponing cross-training when it is possible in the current period is not an optimal action (Lemma 2).

Proof. See Appendix.

The intuition for this result comes from a simple cost-benefit analysis. Basically, what the principal does is comparing the expected costs and benefits of each action at each point in time. The proposition stated above says that there will be a finite time period after which incurring the expected current costs of cross-training is not expected to pay sufficiently in the future. This is determined by the level of cognitive dissonances and the process governing them along with other parameters of the model. When cross-training becomes a non-profitable action, the principal starts to make decisions solely based on specializations of the agents. A direct implication of the main result is that cognitive dissonance might be an equilibrium phenomenon. If it is not worth reducing it to 0 , the individual continues his life feeling the stress and the tension in every instance where he needs to use both selves in a decision-making problem.

The following corollaries present results on some special cases in which either one or both of the agents are completely resistant to habituation.

Corollary 1 (Fixed $\theta_{1}$ and $\theta_{2}$ ) If both agents are totally resistant to habituation i.e. their dissonance terms are constant, the principal does not attempt cross-training and decides according to the specialization of agents.

Proof. See Appendix.

This kind of situation might be observed if an individual has very strong beliefs which are in conflict with each other. An example might be an evolutionary biologist who is a very religious person. On one hand, he believes in creationism and on the other hand, he speaks in favor of evolution in his profession. Both of his beliefs are very strong, and hence do not tend to change.

Corollary 2 (Fixed $\theta_{1}\left(\theta_{2}\right)$ and variable $\theta_{2}\left(\theta_{1}\right)$ ) If agent $A_{i}$ is totally resistant to habituation, i.e., his dissonance term, $\theta_{i}\left(n_{i}\right)=\theta_{i}(0) \forall n_{i} \in \mathbb{N}$ where $n_{i}$ is the number of successful cross-training attempts, then the principal does not attempt to cross-train $A_{i}$. This corresponds to assigning the task in the state $A_{i}$ is not specialized in to agent $A_{k \neq i}$. On the other hand, if agent $k \neq i$ is flexible (i.e. not totally resistant to habituation) the optimal decision rule in Proposition 1 is valid for $A_{k}$, i.e., the principal assigns the task in state $A_{i \neq k}$ is specialized in to $A_{k}$ until $\theta_{k}$ reaches $\bar{\theta}_{k}$ and then starts to assign the task to $A_{i}$.

\section{Proof. See Appendix.}

This kind of situation might be observed if an individual has conflicting beliefs, one of which is very strong and resistant whereas the other is not. 


\section{Comparative Static Analyses}

In this section, we conduct some comparative static analyses and look at the impact of a change in some important parameters of the model on the equilibrium values of dissonances. Those parameters are: the frequency of the composite state, the pace of habituation, and the discount factor. We derive intuitive implications from these analyses and give examples from real life.

\subsection{The Frequency of the Composite Signal}

Proposition 1 An increase in the frequency of the composite signal, $F_{3}$, decreases the equilibrium levels of cognitive dissonances, i.e., $\widetilde{F}_{3}>F_{3} \Rightarrow \widetilde{\overline{\theta_{i}}}<\overline{\overline{\theta_{i}}} i=1,2$.

\section{Proof. See Appendix.}

This is a very intuitive result that we also observe in our daily lives. All it says is that people are less willing to forego current payoffs by investing in something that is not expected to pay back very frequently in the future; or equivalently, an increase in the frequency of future returns (holding returns per-period fixed) makes the investment more attractive. The frequency of expected future payoffs has a major impact on the decision to bear the current costs of an investment project.

\subsection{The Pace of Habituation}

Proposition 2 An increase in the rate of habituation (increase in $\left|\frac{\Delta \theta_{i}}{\Delta n_{i}}\right|$ at every point) decreases the equilibrium levels of cognitive dissonances, i.e., $\widetilde{\theta}_{i}\left(n_{i}\right) \leq \theta_{i}\left(n_{i}\right)$ and $\frac{\Delta \widetilde{\theta}_{i}}{\Delta n_{i}}<\frac{\Delta \theta_{i}}{\Delta n_{i}} \Rightarrow \widetilde{\bar{\theta}_{i}}<\overline{\theta_{i}}$, $i=1,2$.

\section{Proof. See Appendix.}

The pace of habituation is related to the total cost of the investment to be made to achieve the minimal dissonance, since the pace of habituation determines the total opportunity cost of time and payoffs that would be obtained if the agent, who is specialized in the signal was assigned for the task. If the pace of habituation is very rapid, the principal can achieve the minimum level of dissonance in a few cross-training attempts, which makes the opportunity cost very small and hence the investment very profitable. On the other hand, if the pace of habituation is very slow, it will take so many attempts to achieve the minimum level of dissonance, which leads to a very high opportunity cost and makes the investment unprofitable.

Note that the increase in habituation rate is same for all $A_{i}$. If the magnitude of change is assumed to be different among $i$ 's, qualitatively the same result would hold. However, the equilibrium level of conflict would be different depending on the relative flexibility of $A_{i}$ 's. The flexibility/rigidity, in a sense, is related to the easiness (or difficulty) of changing/relaxing/giving up beliefs, traits, habits etc. As the model implies, the more flexible the split-self, easier to cross-train him which leads to a lower dissonance on his side in equilibrium.

\subsection{The Discount Factor}

Proposition 3 An increase in the discount factor $\beta$ decreases the equilibrium levels of cognitive dissonances, i.e., $\widetilde{\beta}>\beta \Rightarrow \widetilde{\bar{\theta}_{i}}<\overline{\theta_{i}} i=1,2$. 


\section{Proof. See Appendix.}

The logic behind this result is very intuitive. An increase in patience implied by an increase in $\beta$ means a higher valuation for future benefits which can be obtained by cross-training. To grasp this result clearly, one might think of two extreme type of individuals one of which is completely myopic (i.e., with $\beta=0$ ) and the other is perfectly forward looking (i.e., with $\beta=1$ ). First one cares only about today and the latter values payoffs in every period equally. First one, when faced with a decision after receiving a signal $s_{j}$ where $j=1,2$, assigns the task to the agent specialized in that signal and the latter may attempt cross-training depending on the value of $\theta_{i}$ and other parameters.

\section{Discussion}

\subsection{Assumptions of the Model and Extensions}

1. Assumptions on Parameters and Functions: In this paper, we assume a simple payoff structure (i.e., a payoff of 1 in the case of success in states 1 and 2 and a payoff of 2 in state 3 ) and a neutral probability distribution over signals (i.e., each signal occurs with probability $\frac{1}{3}$ ). However, our results can be generalized to a large set of payoff structures and signal distributions. The values of thresholds will change but the threshold structure of the optimal decision will remain to be the same.

2. Frequency and Reversal Effects: An interesting extension would be incorporating frequency and reversal effects. These effects refer to the change in dissonance parameters under different cross-training frequencies. In line with the reinforcement learning literature in psychology, one can assume that more frequent cross-training is expected to be more successful in reducing dissonance. On the other hand, the reversal effect refers to an increase in dissonance if cross-training is stopped after it was reduced to 0 . Hence, if the reversal effect is in action, to hold the dissonances of agents at low levels, the principal should continue cross-training even after reaching the minimum level of dissonance. These extensions would enrich the behavioral depth of the model.

3. Learning and Endogenous $\underline{P}$ : Another interesting extension would be endogenizing $\underline{P}$ and incorporating a learning mechanism for agents. Under this setting, the cross-training does not only change dissonance levels but also the perceptive ability of agents. Hence, the successful cross-training attempts increase $\underline{P}$. A direct implication of this is an increase in the tendency for cross-training since an increase in $\underline{P}$ is another motivation for it.

4. Temptation 83 Self- Control Problems: Last of all, implications of incorporating cognitive consistency and cognitive dissonance into temptation and self-control problems (see Gül and Pesendorfer, 2001) in repeated settings is also an open question. It might offer interesting insights into individual and firm behavior.

\section{Conclusion}

We present a dynamic model of individual decision-making problem under cognitive dissonance. Our model also incorporates well-documented cognitive and psychological phenomena such as habituation, modularity of and hierarchy in mind. Our model offers an explanation for the persistence 
of intra-personal conflict and coexistence of conflicting beliefs in the long-run. We conclude that under certain circumstances, conflict and cognitive dissonance might be an equilibrium phenomenon even in an optimizing individual's mind. Specifically, an individual might not find it worthwhile to reduce the conflict between his split-selves. This might be due to some factors such as the specialization levels of split selves in different signals, pace of habituation, frequency of the conflict, and time preference. Comparative static analyses on those parameters give useful insights. An increase in the pace of habituation, the discount parameter, and the frequency of conflict have the same kind of impacts on equilibrium levels of dissonances. They all increase the expected benefit from attempting cross-training. Therefore, an increase in any of these parameters reduces the equilibrium level of dissonance. These results imply some policy suggestions also for the resolution of inter-personal conflict to the managers, politicians and individuals in general. Reducing the costs of attempting cross-training or increasing the expected future benefits are the major ones; and some particular methods to do these can be listed as (i) increasing the frequency of the composite state in which cooperation is necessary, (ii) increasing the value of the cooperation in the composite state, and (iii) providing individuals facilities that would reduce the costs of cross-training (e.g., increasing their perceptive ability in the state they are not specialized in). 


\section{References}

[1] Akerlof, G. A. and Dickens, W. T. (1982) "The Economic Consequences of Cognitive Dissonance", American Economic Review, 72(3), pp. 307-319.

[2] Aronson, E. The Social Animal. New York: Freeman, 1988.

[3] Beauvois, J-L. and Joule, R-V. A Radical Theory of Dissonance. New York: Taylor and Francis, 1996.

[4] Bénabou, R. and Pycia, M. (2002) "Dynamic Inconsistency and Self-Control: A PlannerDoer Interpretation", Economics Letters, 77(3), pp. 419-424.

[5] Berns, G., Cohen, D., and Mintun, M. (1997) "Brain Regions Responsive to Novelty in the Absence of Awareness", Science, 276(5316), pp. 1272-1275.

[6] Blakeslee, S. "This is Your Brain under Hypnosis", The New York Times - Science, November $22,2005$.

[7] Brady, G. L., Clark, J. R., and Davis, W. L. (1995) "The Political Economy of Dissonance", Public Choice, 82(1-2), pp. 37-51.

[8] Brocas, I. and Carillo, J. D. (2008) "The Brain as a Hierarchical Organization", American Economic Review, 98(4), pp. 1312-1346.

[9] Byrne, C. C. and Kurland, J. A. (2001) "Self-deception in an Evolutionary Game", Journal of Theoretical Biology, 212(4), pp. 457-480.

[10] Camerer, C., Loewenstein, G., and Prelec D. (2005) "Neuroeconomics: How Neuroscience can Inform Economics", Journal of Economic Literature, 43(1), pp. 9-65.

[11] Dickens, W. T. (1986) "Crime and Punishment Again: The Economic Approach with a Psychological Twist", Journal of Public Economics, 30(1), pp. 97-107.

[12] Epstein, L. G. and Kopylov, I. (2006) "Cognitive Dissonance and Choice", Rochester Center for Economic Research Working Paper \#525.

[13] Festinger, L. A Theory of Cognitive Dissonance. Stanford, CA: Stanford University Press, 1957.

[14] Fodor, J. The Modularity of the Mind. Cambridge, MA: Bradford Books, MIT Press, 1983.

[15] Gilad, B., Kaish, S., and Loeb, P. D. (1987) "Cognitive Dissonance and Utility Maximization", Journal of Economic Behavior and Organization, 8(1), pp. 61-73.

[16] Gül, F. and Pesendorfer, W. (2001) "Temptation and Self-Control", Econometrica, 69(6), pp. 1403-1435.

[17] Hughlings-Jackson, J. Selected Writings of John Hughlings-Jackson. Ed. J. Taylor, New York, Basic Books, 1959. 
[18] Johansson-Stenman, O. and Svedsäter, H. (2008) "Measuring Hypothetical Bias in Choice Experiments: The Importance of Cognitive Consistency", The B.E. Journal of Economic Analysis and Policy, 8(1), Article 41.

[19] Kahneman, D. and Tversky, A. (1974) "Judgement Under Uncertainty: Heuristics", Science, 185(4157), pp. 1124-1131.

[20] Konow, J. (2000) "Fair Shares: Accountability and Cognitive Dissonance in Allocation Decisions", American Economic Review, 90(4), pp. 1072-1091.

[21] Livnat, A. and Pippenger, N. (2006) "An Optimal Brain can be Composed of Conflicting Agents", Proceedings of the National Academy of Sciences, 103(9), pp. 3198-3202.

[22] McClure, S., Laibson, D., Loewenstein, G., and Cohen, J. (2004) "Separate Neural Systems Value Immediate and Delayed Monetary Rewards", Science, 306(5695), pp. 503-507.

[23] Minsky, M. The Society of Mind. New York, NY: Simon and Schuster, 1986.

[24] Mischel, W., Shoda, Y., and Rodriguez, M. L. (1989) "Delay of Gratification in Children", Science, 244(1907), pp. 933-938.

[25] Oatley, K. (1986) "Conflict and Control Among Mental Agents", Journal of Semantics, $5(2)$, pp. 165-168.

[26] Oxoby, R. J. (2003) "Attitudes and Allocations: Status, Cognitive Dissonance, and the Manipulation of Attitudes", Journal of Economic Behavior and Organization, 52(3), pp. 36585 .

[27] Pinker, S. How the Mind Works. New York, NY: W. W. Norton and Company, 1997.

[28] Rabin, M. (1994) "Cognitive Dissonance and Social Change", Journal of Economic Behavior and Organization, 23(2), pp. 177-94.

[29] Sackheim, H. A. and Gur, R. C. (1979) "Self-deception: A Concept in Search of a Phenomenon", Journal of Personality and Social Psychology, 37(2), pp. 147-169.

[30] Shettleworth, S. J. Cognition, Evolution and Behavior. New York, NY: Oxford University Press, 1998.

[31] Thaler, R. and Shefrin, H.M. (1981) "An Economic Theory of Self-Control", Journal of Political Economy, 89(2), pp. 392-406.

[32] Tversky, A. and Shafir, E. (1992) "The Disjunction Effect in Choice Under Uncertainty", Psychological Science, 3(5), pp. 358-361.

[33] Whalen, P., Rauch, S., Etcoff, N., McInerney, S., Lee, M., and Jenike, M. (1998) "Masked Presentations of Emotional Facial Expressions Modulate Amygdala Activity without Explicit Knowledge", The Journal of Neuroscience, 18(1), pp. 411-418. 


\section{Appendix :}

Proof of Lemma 1. The proof directly follows from the following facts: (i) $\theta_{i}$ for $i=1,2$ is bounded from below by 0 , (ii) Probability of receiving $s_{j}$ is independent across time and equals to $\frac{1}{3}$ for all $j=1,2,3$, (iii) $\underline{P}>0$, and (iv) if $\theta_{i}$ reaches 0 , then it reaches in finite number of periods, i.e., $n_{i}$ that satisfies $\theta_{i}\left(n_{i}\right)=0$ is finite. After finitely many periods with successful cross-training, cross-training will not increase expected future payoffs, after which the principal will decide in accordance with specializations of agents.

Proof of Lemma 2. The proof follows mainly from the fact that $\theta_{i}$ 's are monotonic (decreasing) functions of successful cross-training attempts $\left(n_{i}\right)$ and there is no reversal in $\theta_{i}$ 's. Suppose that at time $t$, a signal $s_{j}$ is drawn, which gives the principal the opportunity to cross-train $A_{1}$ (without loss of generality) and brings an expected payoff $\underline{P}+\beta E V_{\min }\left(j^{\prime}, \theta_{1}^{\prime}, \theta_{2}\right)$ in the case of cross-training. On the other hand, acting in accordance with specializations brings an expected payoff $\bar{P}+\beta E V_{\max }\left(j^{\prime}, \theta_{1}, \theta_{2}\right)$. Since cross-training $A_{i}$ is not optimal now, $\underline{P}+\beta E V_{\min }^{t}\left(j^{\prime}, \theta_{1}^{\prime}, \theta_{2}\right)<\bar{P}+\beta E V_{\max }^{t}\left(j^{\prime}, \theta_{1}, \theta_{2}\right)$ should hold at $t$. Now suppose that $\tilde{t}>t$ is the first period in which the signal $s_{j}$ is drawn again (which again makes cross-training $A_{1}$ a possible action). But since the cross-training was not made at $t$ and distribution of the states of the world is timeindependent, the dynamic problem of the principal at $\widetilde{t}$ is same with the problem at $t$. Therefore, it directly follows from the inequality above that $\underline{P}+\beta E V_{\min }^{\widetilde{t}}\left(j^{\prime}, \theta_{1}^{\prime}, \theta_{2}\right)<\bar{P}+\beta E V_{\max }^{\widetilde{t}}\left(j^{\prime}, \theta_{1}, \theta_{2}\right)$ holds, as well.

Proof of Theorem 1. We start with the possibility that both cognitive dissonances are reduced to their minimum values, i.e., 0 . Let's call the first period in which $\theta_{i}=0$ for $i=1,2$ as $t^{0,0}$. By Lemma $1, t^{0,0}$ is finite with probability 1 . Starting from $t^{0,0}$ onwards, the principal's decision is trivial since cognitive dissonances cannot be reduced anymore. ${ }^{9}$ Therefore, starting from $t^{0,0}$, the principal acts in accordance with specializations for any given signal in each period. Let's call the expected payoff from acting in accordance with specializations starting from $t^{0,0}$ onwards as $\bar{V}$.

By the definition of $t^{0,0}, \exists \theta_{i}$ such that $\theta_{i} \neq 0$ at $t^{0,0}-1$. Since $\theta_{i}=0$ at $t^{0,0}$ and $\theta_{i} \neq 0$ at $t^{0,0}-1$, we can say that the signal at $t^{0,0}-1$ was the one in which $A_{i}$ is not specialized in. So, we can solve the principal's problem backwards starting from $\theta_{i}=0$, for $i=1,2$. If $\theta_{i}=0$ is reached for both agents, whatever decision the principal makes, the stochastic processes in the future are same and given the state of the world, the principal should act in accordance with specializations since there is no expected future benefit from attempting cross-training.

Assume that $\theta_{i}$ reaches 0 in $n_{i}^{0}$ successful attempts. Since the principal knows the processes governing $\theta_{i}$ 's, now when he has value of $\theta_{i}$ that is one successful cross-training away from 0 , he can compare the expected payoff that correspond to acting in accordance with specializations and attempting cross-training. Given the parameters of the model and processes governing $\theta_{i}$ 's, the optimal decision rule can be written as a threshold rule that is described in the proposition.

Continuing in this fashion, the principal can compare expected payoffs for each strategy given the state of the world and current values of dissonances at each period $t$. Therefore, each period decision is determined with the help of a threshold rule presented above. Since we solve the problem in a backward induction fashion, the collection of optimal actions along this path constitute an optimal strategy.

\footnotetext{
${ }^{9}$ Note that what we actually use here is the fact that they are bounded below by 0 , which enables us to use the backward induction argument.
} 
Proof of Corollary 1. Attempting cross-training has expected current costs (e.g., $\bar{P}-\underline{P}$ if $s_{j}=s_{1}$ or $s_{2}$ ) since the principal assigns the signal to the agent who is not specialized in it. On the other hand, it also has expected future benefits if the agent to be cross-trained is open to habituation, i.e., $\theta_{i}\left(n_{i}\right)$ is not a constant function. However, if none of the agents are open to habituation, i.e., for $i=1,2, \theta_{i}\left(n_{i}\right)$ is a constant dissonance function, then there are no expected future benefits from attempting cross-training. In this case, next period value functions in (1) and (2) are identical for all actions at $t$. Therefore, the principal's decision is determined only by the current expected payoff levels. Since in (1), $\bar{P}>\underline{P}$ and in $(2),(\bar{P} \bar{P})\left(2-\theta_{1}+\theta_{2}\right)>(\underline{P} \underline{P})\left(2-\theta_{1}-\theta_{2}\right)$, the principal does not attempt cross-training if both $\theta_{i}$ 's are constant. The equilibrium levels of dissonances in this particular case will be the initial values of $\theta_{1}$ and $\theta_{2}$, i.e., $\bar{\theta}_{i}=\theta_{i}(0)$ for $i=1,2$.

Proof of Corollary 2. This case is similar to the one discussed in the previous corollary with the only difference that one of the agents is open to habituation. Therefore, the reasoning used in the proofs of Proposition 1 and Corollary 1 is valid again. There is no reason to try to habituate the inflexible agent and the decision on the other agent depends on other parameters. The equilibrium level of dissonance for the inflexible agent is its initial value whereas for the flexible agent, the decision rule defined in the main theorem combined with parameter values determines the equilibrium value.

Proof of Proposition 1. The frequency of the composite state affects principal's decision since it directly affects the expected benefit from attempting cross-training. $F_{j}$ terms are hidden in the expectation operator in value function, (1) and (2). In particular, an increase in the frequency of a conflict means a higher marginal expected future return for the cross-training. Accordingly, if $\widetilde{F}_{3}>F_{3}$, then $\widetilde{\bar{\theta}_{i}}<\overline{\theta_{i}}$ since $E \widetilde{V}\left(j, \widetilde{\bar{\theta}}_{1}, \widetilde{\bar{\theta}}_{2}\right)>E \widetilde{V}\left(j, \bar{\theta}_{1}, \bar{\theta}_{2}\right)$ for cross-training. Hence, an increase in the frequency of $s_{3}$ (i.e., $F_{3}$ ) implies a greater tendency for attempting cross-training.

Proof of Proposition 2. We initially assume that for all $i, \frac{\Delta \theta_{i}}{\Delta n_{i}}<0$ at each point, where $n_{i}$ is the number of successful cross-training attempts for agent $A_{i}$ and $\theta_{i}$ is a function defined on natural numbers. Now, assume for all $i, \frac{\Delta \widetilde{\theta}_{i}}{\Delta n_{i}}<0, \widetilde{\theta}_{i}\left(n_{i}\right) \leq \theta_{i}\left(n_{i}\right)$ and, $\frac{\Delta \widetilde{\theta}_{i}}{\Delta n_{i}}<\frac{\Delta \theta_{i}}{\Delta n_{i}}$ at each point $n_{i}$. An increase in habituation rate means that (i) higher (potential) payoffs in the composite state $\left(s_{3}\right)$ will be obtained sooner, i.e., the cross-training investment pays off sooner, and (ii) the opportunity cost of reaching any given level of dissonance is now lower, both of which imply a greater tendency for attempting cross-training. The result follows.

Proof of Proposition 3. The logic behind this result is very intuitive. An increase in patience(i.e., an increase in $\beta$ ) means a higher valuation of future benefits that can be obtained by cross-training. To show this, consider the problem of the principal at any point in time $t$ for any level of $\theta_{i}$, under signal $s_{j}$ which makes it possible to cross-train agent $A_{1}$ (without loss of generality). Assume that $\widetilde{\beta}>\beta$. Denote the expected future returns if cross-training is made by $E V\left(j, \theta_{1}^{\prime}, \theta_{2}\right)$ and the expected future returns if specializations are followed by $E V\left(j, \theta_{1}, \theta_{2}\right)$. As we know, if

$$
\beta\left(E V\left(j, \theta_{1}^{\prime}, \theta_{2}\right)-E V\left(j, \theta_{1}, \theta_{2}\right)\right)>\bar{P}-\underline{P}
$$

then it is optimal to attempt cross-training. But,

$$
\widetilde{\beta}\left(E V\left(j, \theta_{1}^{\prime}, \theta_{2}\right)-E V\left(j, \theta_{1}, \theta_{2}\right)\right)>\beta\left(E V\left(j, \theta_{1}^{\prime}, \theta_{2}\right)-E V\left(j, \theta_{1}, \theta_{2}\right)\right)>\bar{P}-\underline{P}
$$

since $\widetilde{\beta}>\beta$ and $E V\left(j, \theta_{1}^{\prime}, \theta_{2}\right)-E V\left(j, \theta_{1}, \theta_{2}\right)>0$. Since this is valid for any $t, s_{j}$, and $\theta_{i}$, it is also valid for equilibrium values of $\theta_{i}$, which implies $\widetilde{\bar{\theta}_{i}}<\overline{\theta_{i}}$ if $\widetilde{\beta}>\beta$. 